\title{
ANÁLISE DA EFICÁCIA DA HIGIENE ORAL DE PACIENTES INTERNADOS EM UNIDADE DE TERAPIA INTENSIVA EM UM HOSPITAL DE ALTA COMPLEXIDADE DO SUL DO BRASIL
}

\author{
Karoline Cândido Francisco Teixeira ${ }^{1}$ \\ E-mail:karol_mya@hotmail.com \\ Luana Moretti dos Santos ${ }^{2}$ \\ E-mail:draluanamoretti@outlook.com \\ Fabiano Goulart Azambuja ${ }^{3}$ \\ E-mail:bucomax@gmail.com
}

\section{RESUMO}

Introdução: As infecções orais, na Unidade de Terapia Intensiva (UTI), deveriam ser preocupações constantes dos profissionais da área da Saúde ali inseridos, devido às consequências que podem causar na saúde geral dos pacientes debilitados sistemicamente. A criação de um protocolo-padrão de higiene oral é de suma importância para impedir ou tratar tais infecções, o que possibilita ao paciente conforto e qualidade de vida, devendo ser realizada por profissionais qualificados. Métodos: Foi realizado um estudo transversal e descritivo, cuja análise foi descritiva e se desenvolveu na Unidade de Terapia Intensiva de um hospital de alta complexidade no Sul do Brasil, no período de fevereiro de 2016 a fevereiro de 2017. A amostra total foi composta por 35 pacientes, com idade mínima de 18 anos, que estavam internados na UTI do referido hospital, portadores de prontuários e Termo de Consentimento livre e Esclarecido. Resultados: Dentre os microrganismos achados nos exames laboratoriais dos pacientes, apresentaram-se em maior quantidade Klebsiella pneumoniae, Staphylococcus coagulase negativo e Escherichia coli. Apenas dois pacientes adquiriram o Acinetobacter baumannii. A maioria dos pacientes obtiveram bactérias Gram-negativas presentes em sua microbiota oral. Conclusões: As bactérias patogênicas presentes no meio oral devem ser tratadas e erradicadas. Isso pode ser alcançado por meio de um protocolo-padrão de higiene oral. A participação da Odontologia na equipe multidisciplinar no ambiente hospitalar é de fundamental importância para a indicação da terapêutica adequada.

DESCRITORES: CUIDADOS CRÍTICOS; HIGIENE BUCAL; BACTÉRIAS GRAM-NEGATIVAS.

\footnotetext{
Graduanda em Odontologia - Universidade do Extremo Sul Catarinense.

Graduanda em Odontologia - Universidade do Extremo Sul Catarinense.

Doutor em Cirurgia e Traumatologia em Buco-Maxilo-Faciais - Universidade do Extremo Sul Catarinense.
} 
Teixeira KCF, Santos LM, Azambuja FG. Análise da eficácia da higiene oral de pacientes internados em unidade de terapia intensiva em um hospital de alta complexidade do Sul do Brasil. Rev. Odontol. Univ. Cid. São Paulo 2018 jul/set 30(3) 234-45

ISSN 1983-5183

\title{
ANALYSIS OF THE EFFECTIVENESS OF ORAL HYGIENE OF INTERNED PATIENTS IN INTENSIVE THERAPY UNIT IN A HIGH-COMPLEXITY HOSPITAL IN THE SOUTH OF BRAZIL
}

\begin{abstract}
Introduction: Oral infections in the Intensive Care Unit (ICU) should be a constant concern of the health professionals inserted there, due to the consequences that can cause in the general health of systemically debilitated patients. The creation of a standard protocol of oral hygiene is of paramount importance to prevent or treat such infections, allowing the patient comfort and quality of life and should be performed by qualified professionals. Methods: A cross-sectional and descriptive study was carried out, which was descriptive and developed in the Intensive Care Unit of a highly complex hospital in the South of Brazil, from February 2016 to February 2017. The total sample was composed by 35 patients with a minimum age of 18 years who were hospitalized in the ICU of the referred hospital, patients with medical records and a Consent Form, free and clear. Results: Among the microorganisms found in the laboratory exams of the patients, Klebsiella pneumoniae, Staphylococcus coagulase negative and Escherichia coli were present. Only two patients acquired Acinetobacter baumannii. Most of the patients obtained Gram-negative bacteria present in their oral microbiota. Conclusions: The pathogenic bacteria that are present in the oral environment must be treated and eradicated. This can be achieved through a standard oral hygiene protocol. The participation of Dentistry in the multidisciplinary team in the hospital environment is of fundamental importance for the indication of the appropriate therapy.
\end{abstract}

DESCRIPTORS: CRITICAL CARE; ORAL HYGIENE; GRAM-NEGATIVE BACTERIA.

\section{INTRODUÇÃO}

O presente estudo teve como objetivo geral avaliar a eficiência do protocolo operacional padrão de higienização bucal realizada pela equipe de enfermagem nos pacientes internados na UTI pertencente a um hospital de alta complexidade no Sul do Brasil.

Devido à gravidade dos pacientes que se encontram internados e à realização de grande quantidade de procedimentos julgados invasivos, as UTIs são consideradas áreas críticas, por existir um risco maior de desenvolvimento de infecções'. Uma das preocupações frequentes nos hospitais, especialmente em Unidade de Terapia Intensiva, diz respeito à pneumonia nosocomial, por ser a segunda causa mais comum de infecção hospitalar e a responsável por taxas expressivas de morbidade e de mortalidade em pacientes. Essa pneumonia atinge de $10 \%$ a $15 \%$ das infecções hospitalares, sendo que de $20 \%$ a $50 \%$ dos pacientes atingidos vão a óbito. Os pacientes que estão mais sujeitos à pneumonia nosocomial são os internados em unidades de terapia intensiva, sobretudo os que estão com ventilação mecânica, afetando de $20 \%$ a $25 \%$ desses pacientes, com as taxas de mortalidade chegando até a $80 \%^{2,3,4}$.

Os pacientes que se encontram dependentes de auxílio profissional para realização de sua higiene bucal, sobretudo os que estão internados em UTIs, são mais suscetíveis a contrair infecções e patógenos mais virulentos do que aqueles encontrados na flora bucal de pacientes saúdaveis 5 . Por isso a necessidade de dispor equipes multiprofissionais, sempre em qualificação, para atuar na assistência ao paciente grave, pois esse paciente precisa de um tratamento multidisciplinar com monitoramento de todos os órgãos e sistemas ${ }^{6}$. 
Teixeira KCF, Santos LM, Azambuja FG. Análise da eficácia da higiene oral de pacientes internados em unidade de terapia intensiva em um hospital de alta complexidade do Sul do Brasil. Rev. Odontol. Univ. Cid. São Paulo 2018 jul/set 30(3) 234-45

ISSN 1983-5183

A presença dos Cirurgiões-Dentistas na Unidade de Terapia Intensiva é justificada pelo Projeto de Lei 2776/08, que torna obrigatória a presença de Dentistas em todas as UTIs, bem como em clínicas e hospitais públicos e privados que possuam pacientes internados. Esse atendimento específico visa a promover a higiene bucal e a saúde do paciente durante a sua internação, a fim de controlar doenças periodontais e problemas bucais, como também contribuir para a prevenção de infecções hospitalares?

\section{MÉTODOS}

Trata-se de um estudo transversal e descritivo, cuja análise foi descritiva e que se desenvolveu nas UTIs Geral e Cardiovascular de um hospital de alta complexidade no Sul do Brasil, no período de fevereiro de 2016 a fevereiro de 2017. Duas acadêmicas do curso de Odontologia foram previamente capacitadas e calibradas para desenvolver o estudo, acompanhadas por docentes do mesmo curso, e responsáveis pelo setor da unidade hospitalar. O presente trabalho foi submetido ao Comitê de Ética, no ano de 2016, pela instituição proponente: a Universidade do Extremo Sul Catarinense. O número de registro (CAAE) é 53357916.3.0000.0119.

As variáveis independentes utilizadas foram referentes à higiene oral realizada pela equipe de enfermagem nos pacientes internados na UTI. Como variáveis dependentes, têm-se a eficácia dessa higiene oral e, por consequência, a redução de bactérias do meio, assim como uma melhora na saúde bucal e sistêmica desses pacientes. $\mathrm{O}$ trabalho teve como amostragem os pacientes internados na UTI pertencente ao referido hospital, sem categorização de gênero e todos eles maiores de 18 anos. A amostragem é não probabilística, do tipo intencional, com 35 pacientes. Foram incluídos na pesquisa os pacientes que se encontravam internados na UTI do hospital mencionado, todos com 18 anos ou mais e devidamente cadastrados, portadores de prontuários e de Termo de Consentimento Livre e Esclarecido (TCLE) assinado.

Foram excluídos da pesquisa pacientes que foram a óbito ou receberam alta médica, o que não possibilitou a realização de uma segunda coleta salivar para posterior comparação dos dados. 0 presente trabalho é um estudo-piloto na Região Sul do Brasil, e teve como embasamento artigos com assuntos em comum a cerca de Odontologia na UTI, protocolo de higiene oral em pacientes de UTI, importância da atuação odontológica hospitalar, Odontologia hospitalar no Brasil, microbiologia oral e pneumonia nosocomial.

A pesquisa obteve como instrumento de coleta Swab com meio Stuart, contendo meio de cultura e tubo, haste plástica, estéril por meio de raios gamas, ponta de algodão absorvente com alta absorção, indicado para transporte, solução de digluconato de clorexidina a 0,12\%, gaze estéril, espátula de madeira descartável, sonda de aspiração sem marcas definidas. No Swab havia um espaço para identificação da amostra coletada e do paciente, preenchido sempre após a coleta de saliva, contendo nome do paciente, data da coleta e apresentando o "antes" (quando a coleta aconteceu antes da higiene oral realizada pelos enfermeiros) ou o "depois" (quando a coleta aconteceu após higiene oral realizada pelos enfermeiros). No primeiro momento da pesquisa, as pesquisadoras se dirigiram ao hospital nos horários de visitas fixos estabelecidos, que poderiam ser três períodos (manhã, tarde e noite). Realizaram a entrega dos TCLEs aos responsáveis pelos pacientes, informando-os do que se tratava a pesquisa - seus riscos e benefícios - e esclarecendo que a opção pela participação não é obrigatória e não apresenta caráter lucrativo. Tendo compreendido isso, os responsáveis manifestavam suas vontades autorizando ou não seus familiares a participarem da pesquisa. Como estratégia de coleta, a pesquisa se desenvolveu apenas no setor de UTI do referido hospital, uma vez na semana, sempre no primeiro horário da manhã, antes de ser realizada a higiene oral nos pacientes pelos enfermeiros. 
Teixeira KCF, Santos LM, Azambuja FG. Análise da eficácia da higiene oral de pacientes internados em unidade de terapia intensiva em um hospital de alta complexidade do Sul do Brasil. Rev. Odontol. Univ. Cid. São Paulo 2018 jul/set 30(3) 234-45

ISSN 1983-5183

Na sequência foi realizada a higiene oral dos pacientes pela equipe de enfermagem, com Solução de Gluconato de Clorexidina a 0,12\%, embebida em gaze estéril, mas não havia um protocolo-padrão, com variação na quantidade desse material, assim como na utilização ou não de aspiração oral com sonda de aspiração estéril e de espátula de madeira descartável, que usavam conforme julgassem necessário. Observou-se, também, que não houve um padrão de vestimentas para realização da higiene oral por parte dos enfermeiros, que por vezes usavam a roupa-padrão de UTI (calça azul e blusa azul de tecido), mas em outras ocasiões usavam capote cirúrgico estéril descartável.

Todos calçavam luvas de procedimentos descartáveis, mas nem todos faziam uso de máscaras descartáveis. Não seguiam um protocolo de higiene em boca, diversificando quanto ao tempo, forma e modo de realizar a higiene oral. Após efetivação da higiene, foi realizada uma nova coleta de saliva, utilizando um novo Swab. Posteriormente a essa segunda coleta, os Swabs com amostras salivares de antes e depois da higiene oral dos pacientes eram encaminhados pelas pesquisadoras ao setor de procedimentos laboratoriais, localizado no hospital. Por meio dos resultados desses exames, foram observadas as bactérias residentes na cavidade bucal dos pacientes intensivistas, bem como sua patogenicidade. E por intermédio da higienização oral realizada pela equipe técnica de enfermagem, avaliamos a eficácia na redução ou não de bactérias presentes na boca desses pacientes, antes e após a higiene oral realizada pelos enfermeiros.

A análise laboratorial das amostras coletadas ocorreu por meio da cultura geral, com a qual foi possível isolar e identificar bactérias em amostras clínicas e de importância médica. A amostra coletada foi do trato respiratório superior - secreção de orofaringe, por meio de Swab, em que foi realizado esfregaço com diferentes meios de cultura, em uma pequena área de uma placa de Ágar Sangue (AS) e Ágar chocolate Mc Mac Conkey (CHOC), obtida por técnica de semeadura. Com base nesse resultado, foi obtida uma semeadura primária, adequada para o isolamento dos diversos microrganismos que estão relacionados às infecções de diversos sítios anatômicos, tornando-os viáveis ao teste de suscetibilidade aos antimicrobianos. Essa semeadura foi realizada por esgotamento para semiquantificação.

Os esfregaços e a coloração que possam classificar as bactérias com base na morfologia e na reação à coloração pelo Método de Gram, para um diagnóstico rápido, presuntivo de um agente infeccioso, classificam o exame de bacterioscopia. A amostra é recebida em Swab, corada pelo Método de Gram, e sua interpretação é realizada com o objetivo de detectar a ausência ou presença de microrganismos quantificando (ausentes - zero bactérias; raros - uma a cinco bactérias; alguns ou poucos - seis a quinze bactérias; frequentes ou muitos - dezesseis a trinta bactérias; numerosos - maior que trinta bactérias) e classificando quanto a sua morfologia e aos agrupamentos dos microrganismos observados. Os dados coletados foram analisados com auxílio do software IBM Statistical Package for the Social Sciencies (SPSS), versão 22.0 .

As variáveis quantitativas foram expressas por meio de média e desvio-padrão. As variáveis qualitativas foram expressas por meio de frequência e porcentagem. Os testes estatísticos foram realizados com um nível de significância $a=0,05$ e, portanto, confiança de 95\%. A investigação da existência de associação entre as variáveis qualitativas foi realizada por meio da aplicação do teste de Razão de Verossimilhança.

\section{RESULTADOS}

A população total estudada foi composta por 35 pacientes, com idade média de 56,31, sendo a maioria do sexo masculino. $O$ suporte de oxigênio mais utilizado foi do tipo intubação. A maioria dos pacientes 
Teixeira KCF, Santos LM, Azambuja FG. Análise da eficácia da higiene oral de pacientes internados em unidade de terapia intensiva em um hospital de alta complexidade do Sul do Brasil. Rev. Odontol. Univ. Cid. São Paulo 2018 jul/set 30(3) 234-45

ISSN 1983-5183

intensivistas possuem elementos dentários tanto na arcada superior quanto inferior. O perfil descritivo da população encontra-se disponível na Tabela 1.

Tabela 1 - Características gerais da amostra pesquisada ( $\geq 18$ anos). Criciúma, Brasil, 2017.

\begin{tabular}{|c|c|}
\hline & $\begin{array}{l}\text { Média } \pm \text { desvio-padrão ou n(\%) } \\
\mathrm{n}=35\end{array}$ \\
\hline Idade (anos) & $56,31 \pm 16,9$ \\
\hline \multicolumn{2}{|l|}{ Sexo } \\
\hline Masculino & $25(71,4)$ \\
\hline Feminino & $10(28,6)$ \\
\hline \multicolumn{2}{|l|}{ Traqueostomia } \\
\hline Não & $23(65,7)$ \\
\hline Sim & $12(34,3)$ \\
\hline \multicolumn{2}{|l|}{ Intubação } \\
\hline Sim & $18(51,4)$ \\
\hline Não & $17(48,6)$ \\
\hline \multicolumn{2}{|l|}{ Edêntulo } \\
\hline Possui todos os elementos dentários & $16(45,7)$ \\
\hline Edêntulo total & $13(37,1)$ \\
\hline Edêntulo superior & $6(17,1)$ \\
\hline \multicolumn{2}{|l|}{ Ventilação espontânea } \\
\hline Não & $32(91,4)$ \\
\hline Sim & $3(8,6)$ \\
\hline \multicolumn{2}{|l|}{ Máscara de oxigênio } \\
\hline Não & $34(97,1)$ \\
\hline Sim & $1(2,9)$ \\
\hline \multicolumn{2}{|l|}{ Cateter nasal de oxigênio } \\
\hline Não & $34(97,1)$ \\
\hline Sim & $1(2,9)$ \\
\hline
\end{tabular}

Após a coleta salivar realizada antes e depois da higiene oral efetivada pela equipe de enfermagem do respectivo hospital, as amostras coletadas foram encaminhadas para análise laboratorial, obtendo-se como resultado um total de 14 tipos de bactérias e/ou fungos. Dentre os microrganismos encontrados, apresentaram-se em maior quantidade Klebsiella pneumoniae (17,1\%), Staphylococcus coagulase negativo $(14,3 \%)$ e Escherichia coli (11,4\%). Apenas a bactéria Escherichia Coli apresentou resultado diferente para antes $(11,4 \%)$ e depois $(8,6 \%)$ da higiene oral. Os tipos de bactérias ou fungos encontrados na amostra pesquisada estão disponíveis na Tabela 2. 
Teixeira KCF, Santos LM, Azambuja FG. Análise da eficácia da higiene oral de pacientes internados em unidade de terapia intensiva em um hospital de alta complexidade do Sul do Brasil. Rev. Odontol. Univ. Cid. São Paulo 2018 jul/set 30(3) 234-45

ISSN 1983-5183

Tabela 2 - Tipos de bactérias ou fungos encontrados na amostra pesquisada ( $\geq 18$ anos). Criciúma, Brasil, 2017.

\begin{tabular}{lll}
\hline & $\mathrm{n}(\%)$ & $\mathrm{n}=35$ \\
\hline Bactéria ou fungo & Antes & Depois \\
Klebsiella pneumoniae & $6(17,1)$ & $6(17,1)$ \\
Staphylococcus coagulase negativo & $5(14,3)$ & $5(14,3)$ \\
Escherichia coli & $4(11,4)$ & $3(8,6)$ \\
Candida não albicans & $3(8,6)$ & $3(8,6)$ \\
Negativo & $2(5,7)$ & $3(8,6)$ \\
Acinetobacter baumannii & $2(5,7)$ & $2(5,7)$ \\
Proteus mirabilis & $2(5,7)$ & $2(5,7)$ \\
Pseudomonas aeruginosa & $2(5,7)$ & $2(5,7)$ \\
Serratia liquefaciens & $2(5,7)$ & $2(5,7)$ \\
Klebsiella ozaenae & $2(5,7)$ & $2(5,7)$ \\
Streptococcus pneumoniae & $1(2,9)$ & $1(2,9)$ \\
Candida albicans & $1(2,9)$ & $1(2,9)$ \\
Proteus mirabillis e Pseudomonas aeruginosa & $1(2,9)$ & $1(2,9)$ \\
Enterococcus sp e Klebsiella pneumoniae & $1(2,9)$ & $1(2,9)$ \\
Enterobacter sp e Klebsiella pneumoniae & $1(2,9)$ & $1(2,9)$ \\
\hline \hline
\end{tabular}

As bactérias e/ou fungos apresentam diferenciação quanto à estrutura e à patogenicidade (identificada pelo Método de Gram), interferindo diretamente no protocolo de higienização oral a ser adotado individualmente para cada paciente.

Cada estrutura bacteriana possui uma forma de aderência e de resistência sobre a solução digluconato de clorexidina $0,12 \%$, utilizada como protocolo de higiene oral pelo referido hospital.

$\mathrm{Na}$ amostra, a estrutura mais encontrada nos resultados dos exames laboratoriais antes e depois da higiene oral foi do tipo bacilo (71,4\%). Quanto ao Método de Gram, o resultado mais encontrado foi o negativo, totalizando $80 \%$ para antes e $77,1 \%$ para depois da higiene oral realizada.

$\mathrm{Na}$ quantificação bacteriana, os microrganismos que se apresentaram em menor quantidade são intitulados como "raros" e apresentaram-se na amostra 48,6\%, para antes, e 71,4\%, para depois da higiene oral realizada. Os achados dos exames de bacterioscopia e cultura geral encontram-se na Tabela 3. 
Teixeira KCF, Santos LM, Azambuja FG. Análise da eficácia da higiene oral de pacientes internados em unidade de terapia intensiva em um hospital de alta complexidade do Sul do Brasil. Rev. Odontol. Univ. Cid. São Paulo 2018 jul/set 30(3) 234-45

ISSN 1983-5183

Tabela 3 - Exames de bacterioscopia e cultura geral da amostra pesquisada ( $\geq 18$ anos). Criciúma, Brasil, 2017.

\begin{tabular}{|c|c|c|}
\hline & & $\begin{array}{l}\mathrm{n}(\%) \\
\mathrm{n}=35\end{array}$ \\
\hline & Antes & Depois \\
\hline \multicolumn{3}{|l|}{ Estrutura } \\
\hline Bacilos & $25(71,4)$ & $25(71,4)$ \\
\hline Cocos agrupados em cachos & $3(8,6)$ & $3(8,6)$ \\
\hline Não visualizado microrganismo & $2(5,7)$ & $2(5,7)$ \\
\hline Cocobacilos & $1(2,9)$ & $1(2,9)$ \\
\hline Leveduras e hifas & $1(2,9)$ & - \\
\hline Leveduras & $1(2,9)$ & $2(5,7)$ \\
\hline Cocobacilos e bacilos & $1(2,9)$ & $1(2,9)$ \\
\hline Bacilos e cocobacilos & $1(2,9)$ & $1(2,9)$ \\
\hline \multicolumn{3}{|l|}{ Método de Gram } \\
\hline Negativo & $28(80,0)$ & $27(77,1)$ \\
\hline Ausente & $4(11,4)$ & $4(11,4)$ \\
\hline Positivo & $3(8,6)$ & $4(11,4)$ \\
\hline \multicolumn{3}{|l|}{ Quantificação bacterioscopia } \\
\hline Raros & $17(48,6)$ & $25(71,4)$ \\
\hline Moderados & $11(31,4)$ & $6(17,1)$ \\
\hline Ausência de resultados & $2(5,7)$ & $2(5,7)$ \\
\hline Numerosos & $2(5,7)$ & - \\
\hline Numerosas (leveduras e hifas) & $1(2,9)$ & $1(2,9)$ \\
\hline Raros e moderados & $1(2,9)$ & - \\
\hline Numerosos e raros & $1(2,9)$ & - \\
\hline Moderados e raros & - & $1(2,9)$ \\
\hline
\end{tabular}

\section{DISCUSSÃO}

Neste estudo, os homens encontram-se em maior número na amostra, devendo-se isso ao fato de eles não procurarem os serviços de Saúde como forma de prevenção, não tendo o cuidado com a saúde como uma prática masculina e, por esse motivo, apresentam taxas de morbimortalidades significativamente maiores que as das mulheres. Pesquisas nacionais comprovam que há um número maior de homens internados em situação grave e, de modo geral, os homens têm expectativa de vida menor que a das mulheres e morrem em maior quantidade. É perceptível também que as mulheres utilizam mais os serviços de Saúde como forma preventiva e, por isso, há uma situação de saúde distinta quando se trata do grupo masculino comparado ao feminino. Os homens têm uma expectativa de vida menor do que a das mulheres, e taxas de mortalidade por faixa etária deixam evidente que há uma maior mortalidade masculina em todos os grupos etários ${ }^{8}$. 
Teixeira KCF, Santos LM, Azambuja FG. Análise da eficácia da higiene oral de pacientes internados em unidade de terapia intensiva em um hospital de alta complexidade do Sul do Brasil. Rev. Odontol. Univ. Cid. São Paulo 2018 jul/set 30(3) 234-45

ISSN 1983-5183

Em relação às bactérias, podemos defini-las como sendo organismos de uma única célula, cujo material genético não está envolto por uma membrana nuclear especial. Apresentam-se em vários formatos. Os bacilos (em forma de bastão), os Cocos (em forma esférica ou ovalada) e os Espirilos (em forma de sacarolha ou curvada) são as formas mais comuns ${ }^{3}$. O Método de Gram é uma das mais importantes técnicas de coloração na microbiologia, podendo dividir as bactérias em dois grandes grupos: As Gram-positivas e as Gram-negativas, possuindo diferenças de patogenicidade entre elas. As bactérias gram-negativas são causadoras de patogenicidade e as gram-positivas conferem aderência às bactérias de modo geral ${ }^{3}$.

A colonização da orofaringe com bactérias de estrutura do tipo bacilos Gram-negativos, em pacientes com ventilação mecânica, ocorre cerca de 4 a 72 horas após o internamento do paciente na UTI. A quantidade de biofilme tende a crescer com o tempo de internação e os patógenos respiratórios que os colonizam são mais difíceis de destruir, devido à proteção criada pelo biofilme, o que faz as bactérias serem mais resistentes. Essas bactérias também são encontradas na saliva e podem, com facilidade, ser aspiradas da orofaringe para os pulmões, o que pode acarretar a pneumonia9. Uma infecção hospitalar é aquela que não apresenta qualquer indício de estar presente no momento em que o paciente chega ao hospital e acaba sendo adquirida em decorrência de uma hospitalização. A pneumonia nosocomial é a segunda infecção hospitalar mais comum e a causa mais frequente de óbito entre as infecções hospitalares que são o resultado da incidência de três fatores: (1) os microrganismos do meio hospitalar, (2) a condição comprometida ou enfraquecida do hospedeiro e (3) a cadeia de transmissão no ambiente hospitalar. Essa interação dos três fatores proporciona um risco considerável de infecção hospitalar ${ }^{3,4}$.

Também conhecida como pneumonia hospitalar, a pneumonia nosocomial foi definida como:

A) pneumonia adquirida no hospital (HAP), refere-se a qualquer pneumonia ocorrida pelo menos 48 horas após a internação. Comumente tratada na enfermaria e não está associada com ventilação mecânica (VM) ou intubação orotraqueal.

B) pneumonia associada ao ventilador (VAP) é qualquer pneumonia manifestada entre $48 \mathrm{~h}$ e $72 \mathrm{~h}$ após

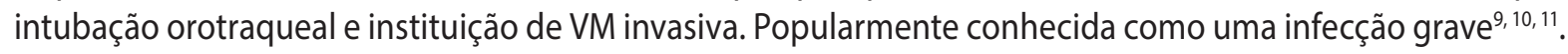

Tanto HAP como VAP proporcionam grande patogenicidade ao paciente quando uma higienização oral deficiente for realizada. Estudos apontam que, em pacientes adultos saudáveis, o organismo que predomina na cavidade oral é Streptococcus viridans. Entretanto, em pacientes críticos a flora oral sofre modificação e se torna predominantemente composta de organismos gram-negativos, tornando-se dessa forma uma flora mais agressiva?.

Nos resultados obtidos no presente estudo, as bactérias mais comuns e encontradas em maior quantidade foram Klebsiella pneumoniae, Staphylococcus coagulase negativo e Escherichia coli. Esses microrganismos não são observados na microbiota oral e orofaríngea de pacientes saudáveis com frequência, contudo podem colonizar a cavidade oral em determinadas situações, como em casos de saneamento precário e de pacientes internados em UTI, ${ }^{9}$.

A Kebsiella pneumoniae é uma espécie de bactéria encapsulada, que tem a forma de um bastonete. É responsável pela causa da pneumonia, mas também pode causar infecções urinárias em pacientes com o sistema imunológico comprometido. A Klebsiella pneumoniae é reconhecida como uma superbactéria, porque sofreu uma mutação genética que fez com que adquirisse resistência a diversos tipos de antibióticos ${ }^{3}$. 
Teixeira KCF, Santos LM, Azambuja FG. Análise da eficácia da higiene oral de pacientes internados em unidade de terapia intensiva em um hospital de alta complexidade do Sul do Brasil. Rev. Odontol. Univ. Cid. São Paulo 2018 jul/set 30(3) 234-45

ISSN 1983-5183

Staphylococcus coagulase negativo é bactéria pertencente à família Micrococcaceae. Ao longo dos últimos 20 anos, a incidência desses microrganismos vem aumentando e eles são atualmente reconhecidos como agentes oportunistas causadores de infecções nosocomiais e comunitárias ${ }^{12,13,14}$.

Escherichia Coli é um dos habitantes mais comuns no trato intestinal humano, é possivelmente o organismo mais conhecido da microbiologia. É o maior patógeno transmitido pelos alimentos. E. coli geralmente são inofensivas, mas certas linhagens podem ser patogênicas $5^{3,15}$.

Nos resultados obtidos com a pesquisa, dois pacientes apresentaram em seus resultados laboratoriais a presença da bactéria Acinetobacter baumanii, e esse resultado constitui um dado alarmante para profissionais intensivistas da Saúde, pois esse microrganismo apresenta alta patogenicidade, como relatado por Tortora et al. ${ }^{3}$ (2012) e Loureito et al. ${ }^{16}$ (2016).

[...] acinetobacter baumanii é uma preocupação entre a comunidade médica devido à rapidez com a qual adquire resistência aos antibióticos. Algumas linhagens são resistentes a todos os antibióticos disponíveis. É um patógeno oportunista encontrado essencialmente em ambiente hospitalar. A resistência aos antibióticos associada com o enfraquecimento da saúde dos pacientes infectados em hospitais leva a uma alta taxa de mortalidade incomum. A. baumanii é basicamente um patógeno respiratório, mas também pode infectar a pele, as feridas, os tecidos conjuntivos, e porventura a corrente sanguínea.

Por intermédio dos resultados obtidos no presente trabalho, observou-se que a falta de um protocolo de higiene oral gerou uma falha nos serviços oferecidos dentro do âmbito hospitalar, acarretando aos pacientes um maior acúmulo do biofilme dental, expondo-os a microrganismos capazes de albergar colônias de patógenos e facilitar o crescimento desses agentes. Também foi possivel analisar que a higiene oral realizada pelos enfermeiros do referido hospital não foi tão eficaz quanto deveria, pois em conformidade com os resultados obtidos conclui-se que os 14 tipos de bactérias encontrados na cavidade oral dos pacientes antes da execução da higiene oral também foram encontrados após o procedimento, ou seja, a higiene oral não erradicou nenhum microrganismo. A Escherichia Coli foi a única bactéria que se apresentou em menor quantidade depois de a higiene oral ser efetuada; nos outros 13 tipos de microrganismos a quantidade permaneceu igual.

A literatura especifica que a ausência de controle do biofilme oral pode piorar as doenças periodontais e a exacerbação dessas doenças durante a internação hospitalar, o que pode contribuir para maiores complicações na saúde do paciente intensivista?.

Como forma de higienização da cavidade oral, a solução digluconato de clorexidina é um antisséptico eficaz até mesmo em baixas concentrações, contra uma variedade de bactérias gram-positivas e gramnegativas, aeróbicas e anaeróbicas e fungos. Essa solução age rapidamente, esterilizando em um período de 30 segundos a 5 minutos, aproximadamente, conforme sua concentração e o tipo de microrganismo a ser destruído; tem ação residual e sua ação bactericida é mais rápida do que a fungicida ${ }^{17,18}$.

As infecções bucais são focos primários das infecções sistêmicas nos pacientes dependentes de cuidados intensivos, portanto medidas precisam ser tomadas para que os procedimentos odontológicos sejam realizados rotineiramente desde 0 tratamento de infecções bucais até cuidados preventivos ${ }^{19}$. Contudo pode-se afirmar a importância de o Cirurgião-Dentista fazer parte do corpo clínico de um hospital, a fim de intervir na saúde oral do paciente e consequentemente melhorar sua saúde sistêmica, conseguindo por meio de um protocolo de higiene oral individual, estabelecido por um profissional da área, ou seja, capacitado para tal cargo, e desenvolvendo atividades multidisciplinares para que dessa forma o paciente seja tratado com equidade e de forma integral. 
Teixeira KCF, Santos LM, Azambuja FG. Análise da eficácia da higiene oral de pacientes internados em unidade de terapia intensiva em um hospital de alta complexidade do Sul do Brasil. Rev. Odontol. Univ. Cid. São Paulo 2018 jul/set 30(3) 234-45

ISSN 1983-5183

Entretanto, na realização de tal pesquisa, notou-se a dificuldade que ainda se tem em inserir o Cirurgião-Dentista em instituições hospitalares, como já relatado²:

[...] o obstáculo frequentemente enfrentado pelo cirurgião-dentista para integrar equipes multidisciplinares em UTI está na baixa prioridade que é atribuída aos procedimentos odontológicos diante de tantas complicações apresentadas pelos pacientes internos.

Isso se deve ao fato de que a presença do Cirurgião-Dentista nos hospitais ainda é pouco difundida, até mesmo entre os profissionais das equipes hospitalares. Faz-se necessário perceber relevância da atuação do profissional de Odontologia nas equipes multidisciplinares de atendimento a hospitalizados, para o cuidado da saúde bucal e, consequentemente, geral do paciente ${ }^{20}$.

\section{CONCLUSÃO}

Mediante a discussão apresentada, podemos concluir que, no hospital mencionado, não se tem uma regularidade na realização do protocolo-padrão quanto à higienização oral dos pacientes. Essa falha de protocolo leva a uma higiene oral deficiente, predispondo o paciente a adquirir novas colônias bacterianas assim como bactérias patogênicas residentes no meio hospitalar, que poderiam ser evitadas ou tratadas com a higiene oral eficaz. Compreende-se, assim, que a participação da Odontologia na equipe multidisciplinar é de fundamental importância para a indicação da terapêutica adequada, promovendo a melhora no quadro de saúde do paciente e proporcionando-lhe qualidade de vida.

Embora os resultados deste trabalho sejam muito importantes, as limitações encontradas referem-se ao fato de ser um trabalho pioneiro, o que dificulta encontrar trabalhos semelhantes para comparação de dados; tem-se que considerar, também, o pequeno tamanho da amostra, devido às dificuldades como óbito dos pacientes, alta médica, o não consentimento de familiares para realização da pesquisa e a dificuldade de se inserir de forma multidisciplinar na equipe intensivista do hospital citado. Salienta-se, assim, a necessidade de maiores estudos acerca do tema e de maiores reflexões a respeito do assunto por toda a equipe de Saúde do referido hospital. 
Teixeira KCF, Santos LM, Azambuja FG. Análise da eficácia da higiene oral de pacientes internados em unidade de terapia intensiva em um

hospital de alta complexidade do Sul do Brasil. Rev. Odontol. Univ. Cid. São Paulo 2018 jul/set 30(3) 234-45

ISSN 1983-5183

\section{REFERÊNCIAS}

1. KAHN S, Mangialardo ES, Garcia CH, Namen FM, Galan Júnior J, Machado WAS. Controle de infecção oral em pacientes internados: uma abordagem direcionada aos médicos intensivistas e cardiologistas. Ciênc saúde coletiva 2010 jun.;15(supl. 1):1819-26.

2. MORAIS TMN, Silva A, Avi ALRO, Souza PHR, Knobel E, Camargo LFA. A importância da atuação odontológica em pacientes internados em unidade de terapia intensiva. Rev bras ter intensiva 2006 dez.;18(4):412-7.

3. TORTORA GJ, Funke BR, Case CL. Microbiologia. 10. ed. Porto Alegre: Artmed; 2012.

4. EL-RABBANY M, Zaghlol N, Bhandari M, Azarpazhooh A. Prophylactic oral health procedures to prevent hospital-acquired and ventilator-associated pneumonia: a systematic review. International journal of nursing studies 2015 Jan;52(1):452-64.

5. FRANCO JB, Jales SMCP, Zambon CE, José F, Fujarra C, Ortegosa MV, et al. Higiene bucal para pacientes entubados sob ventilação mecânica assistida na unidade de terapia intensiva: proposta de protocolo. Arq Med Hosp Fac Cienc Med Santa Casa São Paulo 2014 59(3):126-31.

6. SCHLESENER VRF, Rosa UD, Raupp SMM. O cuidado com a saúde bucal de pacientes em UTI. Cinergis, Santa Cruz do Sul 2012 nov.;13(1):73-7.

7. AMIB. Associação de medicina intensiva brasileira. 2018 [Acesso em: 06 nov. 2018]; Disponível em: http://www.amib.org.br/pagina-inicial/.

8. COSTA-JÚNIOR FM, Maia ACB. Concepções de homens hospitalizados sobre a relação entre gênero e saúde. Psic: Teor e Pesq 2009 mar.;25(1):55-63.

9. AMARAL SM, Cortes Ade Q, Pires FR. Nosocomial pneumonia: importance of the oral environment. Jornal brasileiro de pneumologia : publicacao oficial da Sociedade Brasileira de Pneumologia e Tisilogia 2009 Nov;35(11):1116-24.

10. OKGUN Alcan A, Demir Korkmaz F, Uyar M. Prevention of ventilator-associated pneumonia: Use of the care bundle approach. American j infection control 2016 Oct 1;44(10):e173-e6.

11. MANGER D, Walshaw M, Fitzgerald R, Doughty J, Wanyonyi KL, White S, et al. Evidence summary: the relationship between oral health and pulmonary disease. British dental $j$ 2017 Apr 7;222(7):527-33.

12. KONEMAN EW. Color atlas 1997 and textbook of diagnostic microbiology. In: Koneman, EW. Cocos gram-positivos parte I: Estafilococcos e microorganismos relacionados. Philadelphia: Lippincott, Raven Publishers; 1997.

13. BARRETO MF, Picoli SU. Staphylococcus em um hospital de Porto Alegre (RS). Rev bras anal clin 2008 40(4):285-7.

14. CUNHA Mde L, Sinzato YK, Silveira LV. Comparison of methods for the identification of coagulase-negative staphylococci. Memorias do Instituto Oswaldo Cruz 2004 Dec;99(8):855-60. 
ISSN 1983-5183

15. KIM J, Kim M, Kim S, Ryu S. Sensitive detection of viable Escherichia coli O157:H7 from foods using a luciferase-reporter phage phiV10lux. International journal of food microbiology 2017 Aug 254(11-7.

16. LOUREIRO RJ, Roque F, Teixeira Rodrigues A, Herdeiro MT, Ramalheira E. O uso de antibióticos e as resistências bacterianas: breves notas sobre a sua evolução. Rev Port Saúde Pública 2016 34(1):77-84.

17. NEOBRAX. Clorexidina: relatório técnico. 2009 [Acesso em: 06 nov 2018]; Disponível em: http://www.neobrax.com.br/download/Relatorio-Tecnico-da-Clorexidina.pdf.

18. HAGI A, Iwata K, Nii T, Nakata H, Tsubotani Y, Inoue Y. Bactericidal effects and mechanism of action of olanexidine gluconate, a new antiseptic. Antimicrobial agents and chemotherapy 2015 Aug;59(8):4551-9.

19. SANTOS PSS, Mello WR, Wakim RCS, Paschoal MÂG. Uso de solução bucal com sistema enzimático em pacientes totalmente dependentes de cuidados em unidade de terapia intensiva. Rev bras ter intensiva 2008 jun.;20(2):154-9.

20. SOUSA LVS, Pereira AFV, Silva NBS. A atuação do cirurgião-dentista no atendimento hospitalar. Rev Ciênc Saúde 2014 jan-jun;16(1):39-45.

RECEBIDO EM 24/11/2017

ACEITO EM 28/09/2018 